\title{
Educational Assessment, Evaluation, and Accountability: special issue introduction
}

\author{
James H. Stronge
}

Received: 20 April 2013 / Accepted: 21 May 2013 /

Published online: 1 June 2013

(C) Springer Science+Business Media New York 2013

\section{Teacher effectiveness and teacher evaluation: An international perspective}

Teacher (teachers plural ) A teacher is a person who teaches, usually as a job at a school or similar institution. n-count

evaluate (evaluates 3rd person present) If you evaluate something or someone, you consider them in order to make a judgment about them, for example about how good or bad they are. verb (=assess)

(English Collins Dictionary, online, downloaded 17Mar2013)

\section{Focus of the special issue}

Anyone associated with education-teachers, researchers, parents, and students, themselves - recognizes that the core of education is teaching and learning, and the teaching-learning connection works best when we have effective teachers working with every student every day. While effectiveness can be defined in myriad ways (Cruickshank and Haefele 2001), the essential issue is that we have the most effective teachers possible guiding the learning of students. And, "without high quality evaluation systems, we cannot know if we have high quality teachers" (Stronge and Tucker 2003, p. 3). Teacher evaluation is, first, about documenting the quality of teacher performance; then, its focus shifts to helping teachers improve their performance as well as holding them accountability for their work (adapted from Stronge 2006).

How do we evaluate teachers for effectiveness? Does performance evaluation play a role in teacher development and school improvement? What are international trends and issues regarding teacher evaluation? And what is the nexus between teacher

\section{J. H. Stronge ( $\square)$}

School of Education, The College of William and Mary, 301 Monticello Avenue,

Williamsburg, VA 23187, USA

e-mail: jhstro@wm.edu 
evaluation, teacher effectiveness, and student learning? It is questions such as these that have guided the planning and preparation for this Special Issue of Educational Assessment, Evaluation, and Accountability. More specifically, the aim of the editors and well-known contributing authors is that the collective set of articles presented in the Special Issue will provide an overview of teacher evaluation from an international perspective on what is valued in terms of teacher quality.

\section{Overview of articles in the special issue}

The collection of articles that comprise this Special Issue Educational Assessment, Evaluation, and Accountability provide a set of well-researched and thoughtful articles that move from the macroview to the microview of assessment: What happens in schools that results in student success? Specifically, from the perspectives of both teacher effectiveness and how we evaluate for teacher effectiveness, the special issue explores the impact of teachers on student success. This is an important area of study across the globe.

The opening article in this special issue, An International Comparison Investigating the Relationship between National Culture and Student Achievement, explores the measurable relationship of a country's culture to the student achievement of its students. Additionally, the article provides a compelling comparative analysis of more than 50 countries using PISA data as a measure of student achievement. This article sets the stage for the Special Issue by looking broadly at the impact of selected factors on teaching and learning: Teacher effectiveness and student achievement do not occur in a vacuum; rather they impact and are impacted by the circumstances and situations in which they reside. The context does matter.

In the article, Developing and Assessing Beginning Teacher Effectiveness: The Potential of Performance Assessment, Linda Darling-Hammond, Stephen P. Newton, and Ruth Chung Wei (Stanford University, USA) explore what might be considered one of the most important evaluations of teachers - their pre-assessment for potential effectiveness. In this article they delineate an authentic tool, the Performance Assessment for California Teachers (PACT), for evaluating prospective teachers by examining their abilities to plan, teach, assess, and reflect on instruction in actual classroom practice. As described in the article, the PACT seeks both to measure and develop teacher effectiveness, and this study of its predictive and consequential validity provides information on how well it achieves these goals. The research finds that teacher candidates' PACT scores are significant predictors of their later teaching effectiveness as measured by their students' achievement gains in both English language arts and mathematics.

In the next article, Investigating The "Black Box" of Effective Teaching: The Relationship between Teachers' Perception and Student Achievement in a Large Urban District, Marco A. Muñoz, Julie R. Scoskie, and Diana L. French (Jefferson County Public Schools, Kentucky, USA) note that given need to improve student learning, "there is nothing more important than our classroom teachers." The article focuses on obtaining a deeper understanding of the "black box" (i.e., examining inner processes rather than just outcomes) of effective classrooms as a priority for successful educational reform efforts. Survey research methods were used to compare the 
perceptions about characteristics of effective teaching from teachers previously identified with statistical value-added modeling (i.e., hierarchical linear modeling) as more effective and less effective in elementary reading classrooms. Findings indicated that the more effective teachers value classroom management and organization as the number one characteristic of effective teaching; that, in turn, enables the more effective teachers to focus classroom time on student learning. Implications for theory and practice also are discussed in this mixed-method article.

In the fourth article in the issue, Teacher Evaluation in China: Latest Trends and Future Directions, Shujie Liu (Qufu Normal University, China) and Decheng Zhao (Beijing Normal University, China) follow up on two previous studies of teacher evaluation in China and continue the dialog by analyzing the latest trends in the context of teacher performance pay. With the implementation of teacher performance pay in China in 2009, teacher performance evaluation has become a heated topic. The research study followed two case studies of teacher evaluation practices from Beijing and revealed changes since the implementation of teacher performance pay, such as a more comprehensive teacher evaluation system. The themes identified in their analysis of the connection between teacher evaluation and teacher pay are explored in their article.

In the final article in this special issue, A Cross-Cultural Comparative Study of Teacher Effectiveness: Analysis of Award-Winning Teachers in The United States and China, Leslie W. Grant, James H. Stronge, and Xianxuan Xu (College of William and Mary, USA) take as the purpose of their study to develop a richer understanding of teacher effectiveness through cross-cultural analyses of the practices and beliefs of selected China and US teachers who have received national awards for their teaching. This study was based upon a phenomenological design that used semistructured interviews, classroom observations, and artifacts for data generation/collection of 30 US and China teachers. The study revealed a number of striking similarities and differences between US teachers and China teachers in their patterns of instructional practices and professional thinking. They conclude by noting, "while the cultural contexts and educational systems certainly play a role in the differences between these country's educational outcomes, it is the teachers, in both countries, who directly impact student learning."

\section{Summary}

As discussed above, the primary aim of this Special Issue of Educational Assessment, Evaluation, and Accountability is to enhance our understanding of teacher effectiveness and teacher evaluation from an international perspective. More specifically, the special issue aims to extend and enrich the international picture by providing a larger context within which to examine teacher effectiveness and evaluation practices. It also is our aim that this special issue will provide an international forum for researchers to identify and explore cutting edge developments and ideas in the research and practice of performance evaluation. Additionally, we trust that the collective work represented here is found to be well informed by theory and research and, hopefully, brings new insights that can promote advancement of the field related to how effective teaching and effective evaluation are inextricably related. 
The various frameworks described in the set of papers presented in this Special Issue of Educational Assessment, Evaluation, and Accountability reflect the challenges and opportunities of working with multiple stakeholders to develop and use teacher evaluation as a key lever in improving teacher effectiveness and school improvement. While a single journal issue cannot possibly offer a full range and comprehensive coverage of the contexts and complexities of an issue that is as vast as teacher evaluation, we do hope that the set of articles prove beneficial to work of Educational Assessment, Evaluation, and Accountability's readership. Further, we trust that our collective effort facilitates a better understanding of the competing aspects of technical rationality and political realities, and the seemingly irrationality, in personnel evaluation systems.

I wish to thank the very capable work of the authors who contributed to this special issue. Additionally, I greatly appreciate the generous contributions of Marco Munoz, Leslie Grant, and Shujie Liu as Co-Editors for this Special Issue. Without the quality efforts of this team of international authors and editors, this issue, focused on Teacher Effectiveness and Teacher Evaluation: An International Perspective, would not have come to fruition.

\section{References}

Cruickshank, D. R., \& Haefele, D. (2001). Good teachers, plural. Educational Leadership, 58(5), 26-30. Stronge, J. H. (2006). Evaluating teaching: a guide to current thinking and best practice (2nd ed.). Thousand Oaks, CA: Corwin.

Stronge, J. H., \& Tucker, P. D. (2003). Handbook on teacher evaluation: assessing and improving performance. Larchmont, NY: Eye On Education. 